\title{
Escola i immigració estrangera a Catalunya: la integració escolar
}

\author{
Josep Miquel Palaudàrias \\ Universitat de Girona. Departament de Pedagogia \\ Girona. Spain \\ Jmiquel@zeus.udg.es
}

\section{Resum}

Realitzar una breu exposició sobre la relació entre immigració estrangera i escola a Catalunya és una tasca complexa a causa de la diversitat i precarietat d'algunes de les respostes que s'han donat i pel debat social que genera aquesta qüestió. Per situar el tema es donen, en primer lloc, unes dades que expressen la situació a l'escola pública i privada, posteriorment s'aporten algunes de les respostes educatives que han tingut lloc a l'escolarització de les minories culturals. Finalment, s'aborda la qüestió de la integració escolar partint d'una visió àmplia que inclou una reflexió sobre quin tipus d'integració hi ha i quins són alguns dels seus obstacles.

Paraules clau: política escolar, immigració estrangera, intercultural, integració.

\section{Abstract. School and foreign immigration at Catalonia: the school integration}

It is not easy give a brief account about the relationship between foreing immigration and de catalan schools because there is a wide variety of answers and a precariousness of some of thesse replies. It is also a complex work because of the social debate that these questions create. To talk about this topic first of all we give different data to show the situation between the public and private schools. Later we give sone educational answers which have been given to the schooling of cultural minoritis. Finally, we deal with the integration og minority groupus into school, starting from a wide view that includes a reflection on which type of integration weare talking about and wich are some ot its obstacles.

Key words: education policy, foreign immigration, intercultural, integration.

\section{Sumari}

1. Introducció

2. Dades sobre l'escolarització de les minories culturals

3. Respostes educatives a la diversitat cultural

4. La integració en una societat que cerca la interculturalitat
5. La integració sociocultural dels fills de treballadors estrangers i la integració escolar

6. La integració escolar

7. Bases per a la integració escolar

8. Conclusions

Bibliografia 


\section{Introducció}

Realitzar, en unes breus pàgines, un repàs pel que ha estat i és la relació entre immigració estrangera i escola a Catalunya en els darrers anys, és una tasca complexa, atesa la diversitat de situacions viscudes, la complexitat del tema i la dimensió del debat social que aquest fet comporta per a la societat, en ser l'escola, i no tant l'educació, i la immigració, dos components importants del pols social quotidià. Enfront d'aquesta situació, l'opció ha estat la de presentar a les primeres pàgines les dades més recents pel que fa a la presència d'alumnes d'origen immigrant als centres d'educació obligatòria, per tal de realitzar una aproximació quantitativa al fenomen, posteriorment és dóna pas a presentar un breu resum qualitatiu de les respostes que l'escola ha donat a la diversitat cultural en els darrers anys. Totes dues aproximacions han tingut com a rerefons una anàlisi a cavall de l'escola pública i de l'escola privada concertada. A continuació, s'ha abordat la qüestió de la integració escolar partint d'una visió àmplia sobre quin tipus d'integració hi ha en una societat que cerca la interculturalitat, per passar a fer una anàlisi de la dimensió de la integració escolar, abordant quins són els obstacles i quines són les seves condicions, tenint com a referent la situació que es viu a les escoles de Catalunya.

\section{Dades sobre l'escolarització de les minories culturals}

Per tal de situar la presència de l'alumnat d'origen immigrant en els centres d'educació obligatòria, s'exposaran algunes dades que mostraran, des de la perspectiva quantitativa, la seva situació escolar. Aquesta exposició pretén, per una banda, relativitzar l'espectacularitat amb la qual alguns sectors de la societat han abordat la situació de les minories culturals als centres educatius i, per l'altra, situar la dimensió on es donen les problemàtiques educatives que l'escola viu. Es prendran com a referents les dades dels cursos escolars 1998-1999 i 1999-2000 que són les darreres que ha facilitat el Departament d'Ensenyament (quadre 1).

En els cursos respectius el percentatge total d'alumnat categoritzat com a estranger era de l'1,8\% i del 2,18\%. Aquestes quantitats mostren que, en relació amb la totalitat d'alumnat, la seva presència és encara poc significativa, tot

Quadre 1. L'escolarització d'alumnat d'origen immigrant segons sectors i nivells educatius.

\begin{tabular}{lcc}
\hline & Curs 1998-1999 & Curs 1999-2000 \\
\hline Educació infantil pública & $2,2 \%$ & $2,4 \%$ \\
Educació infantil privada & $0,7 \%$ & $0,9 \%$ \\
Educació primària pública & $3,0 \%$ & $3,5 \%$ \\
Educació primària privada & $0,6 \%$ & $0,7 \%$ \\
ESO pública & $2,7 \%$ & $3,7 \%$ \\
ESO privada & $0,6 \%$ & $0,8 \%$ \\
\hline
\end{tabular}

Font: Departament d'Ensenyament. 
i que amb tendència al creixement. Per tant, no es pot parlar d'una situació generalitzada i menys amb un caràcter problemàtic general com algunes vegades posen de manifest alguns mitjans d'informació. En tot cas, cal tenir en compte que el creixement és un degoteig més o menys constant que afecta la dinàmica d'algunes escoles i que preocupa de forma considerable els professionals a causa del replantejament educatiu que representa l'entrada d'alumnes un cop iniciat el curs.

Si se situen les dades diferenciant entre el sector públic i el sector privat, s'observa la important distància que hi ha entre uns centres i els altres, circumstància que evidencia, un cop més, que les reivindicacions d'alguns professionals i sindicats, per tal de repartir l'alumnat estranger a través d'un acurat procés de matriculació entre centres públics i concertats, i la necessitat de replantejar seriosament els recursos que reben alguns centres, tenen sentit quan se situen sobre l'alumnat que porta més feina als CEIP $\mathrm{i}$ instituts per la seva situació de dèficit sociocultural causada per la feblesa que tenen les polítiques d'integració.

Aquestes dades, situades per tipologia de centres, mostren que als centres d'educació infantil i primària (CEIP) públics, el percentatge d'alumnat estranger era del 2,74\% el curs 1998-1999 i del 3,10\% el curs següent. En els centres d'ESO els percentatges són els exposats al quadre.

Situats sobre els àmbits provincials i diferenciant entre CEIP i instituts d'ESO (quadre 2), per tal de copsar la relació entre el total d'alumnat i els alumnes estrangers, es posa de manifest que, tant en un cas com en l'altre, és la província de Girona ${ }^{1}$ la que presenta un percentatge superior, el 5,2\% i el $6 \%$ respectivament, seguida de la província de Barcelona amb uns percentatges del 3\% i del 3,6\%. En aquest darrer espai el pes de Barcelona com a municipi té una significativa rellevància, ja que en aquesta ciutat el percentatge és del $5,9 \%$. A les altres dues demarcacions els percentatges són inferiors, tot i que també cal tenir en compte la seva evolució a l'alça.

Quadre 2. Presència d'alumnes estrangers en els centres públics d'educació obligatòria per províncies.

\begin{tabular}{llc}
\hline & \multicolumn{2}{c}{ Curs 1999-2000 } \\
\cline { 2 - 3 } & CEIP & ESO \\
\hline Barcelona & $3,0 \%$ & $3,6 \%$ \\
Girona & $5,2 \%$ & $6,0 \%$ \\
Lleida & $1,7 \%$ & $2,4 \%$ \\
Tarragona & $2,5 \%$ & $2,5 \%$ \\
\hline
\end{tabular}

Font: Departament d'Ensenyament.

1. Cal recordar que la província de Girona és la que presenta una proporció més elevada de població d'origen immigrant en relació amb la població total. 
Prenent com a referència les dades del Departament del darrer curs pel que fa a zones d'origen, són els alumnes del Magrib els que tenen una presència més elevada entre els estrangers, el 50,9\% als CEIP i el 53,3\% als instituts d'ESO, tot i que el seu percentatge en relació amb la totalitat de l'alumnat és minso, l'1,6\% i l'1,9\% respectivament. L'altre grup important són els originaris de l'Amèrica Central i de Sud-amèrica, que representen aproximadament la meitat dels magribins i és el grup que mostra un creixement més elevat al llarg del curs 1999-2000 als centres de secundària.

Situant les dades sobre centres públics i privats, s'observa que l'alumnat d'origen comunitari té una presència més equilibrada, per exemple, en relació amb els magribins, ja que els primers representen el $0,12 \%$ i els segons, el $0,16 \%$ del total. Situació que no es produeix als centres públics per l'important pes dels alumnes extracomunitaris.

Les problemàtiques en l'escolarització de l'alumnat d'origen immigrant, que és l'originari dels "països empobrits", són, bàsicament, conseqüència de la seva concentració a municipis i barris, sovint en una situació de certa degradació social a causa d'una escassa acció en el tema de l'habitatge, dins de les deficitàries polítiques dirigides a la integració de les persones d'origen immigrant, situació que es reflecteix en la vida d'alguns centres escolars públics, àmbit on els percentatges d'alumnes estrangers en relació amb la població del centre creixen de forma important, i que en algunes situacions arriben fins al 50\% de la població escolar. Entre els casos més significatius es troben els de Ciutat Vella a Barcelona i els d'altres municipis del gran cinturó industrial de la província de Barcelona, Osona i de comarques de la província de Girona, com l'Alt i el Baix Empordà i la Selva, entre altres referents.

\section{Respostes educatives a la diversitat cultural}

L'arribada de la diversitat cultural com a part del discurs pedagògic oficial i la presència d'un nombre creixent d'alumnes d'origen estranger als centres educatius, sobretot públics, ha suposat per a la vida escolar un canvi significatiu, ja que les escoles de Catalunya han estat uns dels principals motors de la normalització lingüística i cultural de la societat catalana a partir del canvi democràtic dels anys setanta.

L'escola, amb l'impuls del discurs de la diversitat cultural i més concretament amb el de l'educació intercultural, veu que la seva funció tradicional, que respon, bàsicament, a un model ètnic i nacional, ha de ser canviat pel d'una escola que ha de passar d'una tasca de catalanització a acceptar la funció de ser un agent d'obertura a unes llengües i cultures que no tenen prestigi cultural ni social entre la població de recepció i, simultàniament, ha d'assumir el fet de treballar amb una dimensió sociocultural de més pes que la viscuda fins ara, a causa de la deficitària situació que presenten algunes de les famílies de treballadors estrangers, i per la qual no té ni els suficients recursos educatius ni els professionals amb la formació específica requerida, per tal de respondre a la complexitat i novetat de la situació. Si a aquestes circumstàncies s'afegeix la 
situació que viu l'escola pública en relació amb els centres concertats, pel que fa a l'atenció a les minories culturals, ens trobem en un moment de desprestigi per a la primera, ja que, segons alguns sectors de la població, els centres públics no responen al model de qualitat de l'ensenyament que volen per als seus infants $i$ adolescents $i$, en conseqüència, abandonen aquest model d'escola per passar a una escola concertada que teòricament ofereix una qualitat d'ensenyament més elevada, quan de fet el que fa és una funció més selectiva. Enfront d'aquesta situació, l'Administració educativa no dóna una resposta ferma i sembla que ignori que afavorint l'abandonament dels centres públics possibilita més fragmentació social.

Dins d'aquest panorama va ser el Programa d'Educació Compensatòria ${ }^{2}$, destinat a atendre les desigualtats socials i culturals, el responsable de donar les primeres respostes educatives als mestres d'aula i als centres escolars que es qüestionen què han de fer amb l'alumnat nouvingut o bé com poden atendre'l per tal de millorar la seva escolarització. També hi ha intervingut, i amb més força que l'anterior, el Servei d'Ensenyament del Català (SEDEC) pel que fa a la tasca d'aprenentatge del català, ja que és el responsable del procés d'immersió lingüística que es du a terme. És des d'aquest servei des d'on s'aplica el concepte d'alumnes d'incorporació tardana, per tal d'indicar que s'incorporen a l'escola un cop iniciat el curs i amb un minso domini del català. Un altre servei que hi ha intervingut són els equips d'atenció psicopedagògica (EAP).

En aquests darrers deu anys, les tasques realitzades pels diferents serveis, per tal de respondre als reptes educatius que presenten els infants i adolescents d'origen immigrant, per a tota la comunitat educativa han estat diverses i el cert és que en el cas d'alguns professionals, més que en els programes oficials ${ }^{3}$, s'han abandonat alguns dels principis de l'educació compensatòria per passar a unes actuacions més properes a l'educació intercultural. Procés de canvi que, com analitza Besalú (1996), necessita un impuls més gran per part dels responsables educatius, que han de saber recollir el que en alguns centres educatius ja es fa.

No obstant això, l'assimilació continua tenint un pes important en la tasca educativa de l'escola, que en alguns CEIP es manifesta, per exemple, fent dels dèficits d'aprenentatge a causa de situacions socials o culturals, problemes d'aprenentatge que equiparen aquests alumnes a infants amb necessitats educatives especials (NEE), malgrat que no siguin alumnes amb discapacitats d'aprenentatge. Tan sols els cal una atenció educativa comprensiva amb la seva situació. També en diversos centres de secundària es viu amb gran conflictivitat social i educativa l'escolaritzacio dels infants d'origen immigrant. En alguns

2. Aquest programa té el seu origen en l'aplicació de l'educació compensatòria que impulsa el govern del PSOE els primers anys de mandat d'acord amb els governs autonòmics. També és conegut com a programa per a nens àrabs i gitans.

3. Tot i que el Departament d'Ensenyament ha editat un document orientador sobre què ha de ser l'educació intercultural dins del desplegament curricular. 
casos per la difícil situació social de les famílies i l'alumnat, en altres, per l'absència d'una clara i decidida acció pedagògica d'alguns professionals per respondre als interrogants educatius que plantegen aquests alumnes. Aquesta situació ha comportat que, en els darrers cursos, s'impulsés, des del SEDEC i en els centres de secundària, els tallers d'adaptació escolar (TAE).

Els TAE són unitats en alguns casos externes als centres, però que pertanyen a la seva organització. Tenen per objectiu atendre l'alumnat de cultures i llengües diferents de la llengua d'ensenyament, per tal de dotar-lo del nivell lingüístic bàsic i dels coneixements necessaris del sistema educatiu que li permeti seguir l'escolarització amb el millor rendiment acadèmic possible. Aquest és, inicialment, un projecte transitori, però que de vegades s'allarga de forma considerable més enllà d'un curs, a causa de l'actitud d'incomprensió i segons com de rebuig de les circumstàncies educatives que alguns professors mostren vers l'alumnat de minories culturals. Amb aquest aillament, de vegades monocultural per l'origen nacional dels alumnes o bé per la seva situació sociocultural que viuen en relació amb els altres escolars, es corre el risc d'afavorir un procés de socialització fragmentat que afecta tot l'alumnat i que sembla que aplica a uns una pedagogia de l'èxit $i$ als altres una pedagogia del fracàs escolar, que a la pràctica comporta "diferents sistemes educatius per als diferents col.lectius, dins mateix de l'escola pública o finançada amb recursos públics» (Carbonell, 2000: 112).

\section{La integració en una societat que cerca la interculturalitat}

El projecte intercultural es desenvolupa dins d'un model social basat en el pluralisme cultural que promou i és promogut per la recerca de la convivència harmoniosa en una societat ètnicament, culturalment i lingüísticament diferenciada. La interculturalitat valora positivament la diversitat i cerca l'enteniment i la interacció entre els individus, entén que totes les persones tenen quelcom per aportar i per aprendre en un model social i cultural que reconeix i es reconeix en la diversitat.

Aquest procés polític i social no es pot forçar, exclusivament, legislant l'espai social i cultural, regulant la immigració. S'ha de produir des d'una aproximació voluntària, és a dir, per la iniciativa dels individus i dels col-lectius que volen crear un espai públic, a través d'una cultura comunitària i democràtica (Tourain, 1994) on s'ensenyi a intercanviar opinions, creences, valors i pràctiques socials, amb l'objectiu d'aconseguir una comunicació que doni capacitat de comprensió sobre el que succeeix al seu entorn per transformar-lo.

Aquests àmbits han de ser emparats per un marc legal i social fonamentat en el dret a la ciutadania per a tothom, no solament a nivell discursiu, amb l'objectiu d'afavorir la superació de les barreres que sovint es construeixen entre els grups culturals i que se sustenten essencialment en:

1. El desconeixement que tenen dels altres i la construcció d'aquests a través dels estereotips. 
2. La discriminació dels altres a través de creences morals i religioses que condueixen a la demonització de les cultures i a la intolerància.

3. La discriminació a partir de la limitació de drets que afecten el lliure exercici de la ciutadania.

Un principi de realitat ens mou, lentament i amb sotracs, cap al desenvolupament d'una societat plural que es manifesta en l'intercanvi i la simbiosi que s'ha produït, històricament, entre les poblacions d'origen immigrant i les autòctones. Per aconseguir la integració plural caldrà posar l'accent en les condicions en què es dóna el procés.

La interculturalitat entén la cultura com un element divers i dinàmic que és el resultat de la capacitat creadora i d'aprenentatge de la humanitat. Proposa un model social, en contínua construcció, que tendeix cap a una nova síntesi cultural, construïda a partir dels models culturals presents en la societat i que s'incorporen a una cultura nacional des de la renovació.

En aquest procés renovador el dret a la diferència té un pes específic i significatiu, però la interculturalitat no es construeix sobre aquesta, sinó sobre la unitat, sobre uns patrons universals elaborats a partir de «la recerca d'una síntesi entre la universalitat $i$ la pluralitat en un projecte de convergència entre les societats d'un món» (Liazu, 1992: 13) i sobre el respecte crític i l'assumpció de la diversitat.

La interculturalitat té una dimensió política perquè lluita contra les desigualtats i contra el racisme; té una dimensió social interactiva perquè proposa la creació d'espais comuns i d'una cultura a partir de l'intercanvi entre les cultures, i és emancipadora perquè defensa els drets de tota la població enfront de l'opressió d'una cultura dominant que obstaculitza la solidaritat entre les persones a través del consumisme, de les condicions de treball i de la legitimació de les desigualtats.

La interculturalitat també ha de tenir en compte les dimensions econòmica i jurídica. Cal lluitar per millorar les condicions en què gran part de la població realitza la inserció laboral i la feblesa en què es mou l'estabilitat laboral, dins d'una societat qualificada de mercat per un discurs neoliberal que cerca la divisió de la societat, donant a les persones diferents drets segons el seu estatus econòmic i laboral.

En aquest projecte, la integració de tota la població ha de basar-se, fonamentalment:

1. En els drets i deures que tota persona té en un context democràtic, fonamentat sobre l'autonomia i a partir de la capacitat de participació de tothom en el procés d'integració. Per Costa-Lascoux (1991) la integració cal negociar-la i edificar-la a través d'avaluacions constants i no pot ser unilateral.

2. En el dret de tothom de dirigir-se cap a la construcció d'una societat que no es fragmenti entre immigrants i nacionals, sinó cap a una societat formada per ciutadans $i$ ciutadanes amb els mateixos drets i amb capacitat per reconèixer-se en els universals, de forma que la diversitat d'orígens, de capacitats 
i de característiques socials i culturals sigui reconeguda com un element comú a tota la població.

Per tant, el concepte d'integració ha de construir-se sobre la pluralitat i amb l'objectiu d'aconseguir la convivència, que és un procés basat en una interacció harmoniosa que implica aprenentatge, tolerància, regulació dels conflictes i, per tant, elaboració de normes comunes, construides sobre aquells elements que uneixen cercant els universals i amb eines per aconseguir la igualtat (Malgesini i Giménez, 1997).

La pluralitat és concebuda a través de la interdependència entre els membres d'una societat i de la possibilitat de recreació i d'intercanvi entre les parts implicades. Aquesta concepció desenvolupa un projecte sociocultural on la diversitat social i cultural és reconeguda com una realitat que possibilita la comprensió i l'abastament de les problemàtiques socioculturals i que comporta un canvi social basat en l'obertura als altres, per tal de trencar els murs que separen socialment i culturalment i obrir un procés crític sobre l'etnocentrisme.

La necessitat d'obrir-se a la pluralitat afecta per igual a la diversitat de participants, l'etnocentrisme regeix les concepcions i les relacions entre els grups implicats, perquè aquests han construït els seus valors tancant-se sobre si mateixos i sovint en oposició.

La solidaritat és la columna vertebral de la convivència i comporta compromís i suport amb el que està en situació de desigualtat. Solidaritat no és beneficiència.

La recerca d'una cultura i d'una organització social que es fonamenta en la pluralitat persegueix un model social que superi la coexistència i que defugi la dominació, per construir un diàleg horitzontal entre cultures i pobles, del qual són responsables els ciutadans com a elements vitals i creatius de les institucions $i$, per tant, de les dinàmiques d'integració social i cultural. Per Abdallah-Pretceille (1993: 23), "Interrogar-se sobre la integració dels immigrants és interrogar-se sobre les modalitats actuals de participació en la vida social, econòmica, intel.lectual i cívica. Aquestes modalitats evolucionen en funció del temps i de la conjuntura».

\section{La integració sociocultural dels fills de treballadors estrangers i la integració escolar}

Per abordar el procés d'integració d'aquest sector de la població, cal aclarir alguns dels elements que pesen de forma considerable en les propostes i accions que es duen a terme, ja que condicionen les polítiques d'integració dirigides als infants i adolescents d'origen immigrant:

1. Gran part dels infants i joves que es categoritzen com a alumnes immigrants no ho són. Molts han nascut a l'Estat espanyol o fa prou temps que viuen entre nosaltres. Per tant, $\mathrm{i}$ independentment de la seva nacionalitat, 
es pot parlar de persones que formen part del teixit social a través de la seva participació com a població que cerca un lloc en la societat.

2. Les problemàtiques d'aquests joves no giren, solament, a l'entorn del procés migratori. Són comunes a les dels joves que viuen el mateix procés social. Són la conseqüència de les condicions en les quals viuen els marginats i els exclosos, que en aquest cas adquireixen una particular dimensió a causa de la creixent conflictivitat (intolerància, racisme, xenofobia...) que viu la població d'origen immigrant.

Per tant, «no són els individus com a tals els que ens preocupen, sinó els processos socials, és a dir, les relacions socials en què ells són implicats. En aquesta perspectiva, les qüestions de la immigració concerneixen tant els [autòctons] d'arrel com als immigrants» (Noiriel, 1989: 220).

Realitzats aquests breus, però imprescindibles, aclariments, cal passar a fer una anàlisi de les condicions i circumstàncies que és important tenir en compte en el disseny de les polítiques d'integració dirigides a aquests infants i joves:

a) L'al.lusió a una cultura situada en l'origen és un mite. Per a aquests, els referents socioculturals són aquells que troben en el barri o en el poble on viuen, en les experiències entre companys i en els conflictes del seu entorn, més que en el poble o la vila d'origen ${ }^{4}$. Per a ells parlar de cultura magribina és un referent poc clar.

b) Cal tenir en compte la pressió familiar per conservar la identitat en una societat que rebutja la cultura d'origen. També cal ser conscients de les condicions en què es realitza la transmissió de valors, en el si d'una família i una comunitat que viuen importants dificultats en el procés d'integració. Dins d'aquesta situació els joves viuen un significatiu debat intern entre els valors familiars i els valors rebuts a través de l'escolarització i de les relacions amb els companys i companyes, així com de l'espai públic.

c) Cal tenir en compte que la cultura i els referents socials que han construït al llarg del seu desenvolupament estan subjectes a una diversitat de causes, entre les quals destaquen:

- Les condicions laborals en què treballen els adults.

- El nivell de formació dels adults.

- El valor que té l'educació escolar per als pares i el propi procés d'escolarització.

- L'acceptació o el rebuig en els seus contactes amb la societat de recepció.

d) La societat d'assentament ha actuat i actua, fonamentalment, assimilant socialment i culturalment la població d’origen immigrant a través de la

4. La dimensió nacional, cultural, geogràfica... (Marroc, Islam, Magrib) que en els països d'immigració s'utilitza per parlar de la cultura d'origen de les famílies per exemple marroquines, es mostra distant de la realitat social i cultural dels infants i joves. Per a ells la referència d'origen és en tot cas la vida del nucli on es vivia o duar, on la tradició popular i, en el seu cas, la ruralitat tenen un pes específic. 
feina i de l'escolarització. El propi procés assimilador els ha demostrat que aquest no es dóna en l'àmbit dels drets laborals, socials..., i sí a través de la renúncia a la cultura i a la llengua, entre altres elements. Aquest procés assimilador condiciona fortament una avaluació personal i col-lectiva de les possibilitats d'integració.

Per tant, tota política d'integració dirigida a les segones generacions ha de recolzar en dos eixos (Roux, 1989):

1. Accions per tal d'aconseguir la igualtat entre els joves, basades en la idea que aquestes no han de ser diferents per als uns i per als altres. Per tant, aquestes han d'afectar per igual i han d'equilibrar les possibilitats de tota la joventut en la seva capacitat de participació social.

2. Actuacions contra el racisme i contra tot mecanisme d'exclusió, amb la finalitat d'aconseguir una societat conscient que aquests són el producte d'interessos que volen justificar les desigualtats. Aquestes accions s'haurien de basar en dos pressupòsits:

a) Que tota societat és diversa en les formes d'entendre la cultura, la societat, les capacitats i que cal situar tots aquests elements com a referents dinàmics.

b) Que les posicions que pretenguin donar una foto fixa de la cultura, de la societat i de les capacitats, afavoreixen els interessos d'un grup que pretén obrir escletxes en el dret a la igualtat que tota persona, autòctona o immigrant, té.

Aquestes accions han d'afavorir l'enfortiment de la cultura i de la identitat dels joves i la seva capacitat de resposta enfront dels reptes d'una societat cada cop més complexa. Han de promoure la creació d'associacions, preferentment de tipus local, com a conseqüència de polítiques comunitàries, que defensin els drets de tota la població a través de la solidaritat i amb capacitat d'organitzar serveis que donin respostes a les seves necessitats. Els responsables polítics han de tenir en compte que el racisme creix quan falla l'acció social, quan és negada per raons molt variades — crisi institucional, incapacitat d'intuir un conflicte social que és negociable, etc.- la possibilitat de modificar les complexes relacions socials existents (Tabboni, 1996).

\section{La integració escolar}

L'escola és una institució que històricament ha estat l'encarregada de transmetre un model cultural i nacional d'integració. La transmissió d'aquest model, des de la construcció dels sistemes escolars nacionals, es fonamentava en la pretensió que els estats estaven conformats per mitjà de la uniformitat i, en conseqüència, l'escola havia de contribuir a mantenir l'homogeneïtat mitjançant un model escolar que es fonamentava, bàsicament, en una llengua i una cultura. 
Per altra banda, la societat mostra, en les darreres dècades, una ràpida evolució en les seves relacions i capacitats de comunicació, no sempre amb resultats positius per a tothom, però que han dut a qüestionar la tasca formativa $\mathrm{i}$ informativa que l'escola tenia encomanada amb certa exclusivitat.

Aquests canvis socials comporten que avui la societat i en particular els educadors es qüestionin:

a) Si l'escola ha de continuar i pot fer-ho amb el paper integrador que històricament se li ha atribuït.

b) Quins són els obstacles per exercir la funció integradora que l'escola abans realitzava.

c) Quins són els fonaments que avui es consideren necessaris per realitzar la tasca integradora.

Centrat el debat sobre la integració de l'alumnat d'altres orígens culturals, però sense oblidar la resta d'alumnat, cal tenir en compte que la condició bàsica perquè l'escola pugui mantenir un paper integrador és que aquest ha d'anar en connexió amb un projecte integrador que també s'ha de donar en altres àmbits socials, fonamentalment el del treball i també en els que dibuixen els drets socials (habitatge, sanitat, promoció de la dona...). Aquestes actuacions han de basar-se en un pla de sensibilització i de progrés, de tipus comunitari, que ha de contribuir a la formació de la persona i de la societat.

Una breu i prèvia anàlisi per tal de situar el que es tendeix a fer en l'actualitat per tal d'afavorir la integració escolar, mostra que gran part de les polítiques educatives i socioculturals posen èmfasi en la integració obviant, almenys en part, el context sociocultural que viuen els infants i els adolescents $i$, en general, no es té en compte el procés migratori —emigració i immigracióque la família, i en ocasions els propis alumnes, han experimentat més o menys recentment. Per exemple, hi ha poca preocupació pel valor que l'educació té per a les famílies d'origen immigrant i sobre la situació escolar que han viscut algunes persones al país d'origen. Sovint, tampoc no es tenen en compte les causes del procés migratori ni les condicions en les quals es realitza. Circumstàncies que expliquen algunes de les dificultats de relació entre l'escola i els pares i que poden orientar possibles accions pedagògiques destinades a mostrar-los quines són les característiques del procés escolar i de la institució - la cultura escolar-, així com dels conceptes de drets i deures en l'àmbit educatiu al país on ara viuen i de la funció que té l'escola en el país d'arribada que millorarien la relació a la comunitat educativa.

La integració escolar és un procés que ha de tenir com a objectiu assumir la diversitat i la necessitat d'integrar totes les cultures per tal de recollir les seves aportacions al món escolar, construint una nova cultura nacional sobre la base de la pluralitat cultural existent i sense oblidar que l'escola no pot donar solució a les mancances del model social i polític en el qual es troba immersa. Cal recordar que l'escola ha d'assumir el que és, solament el que és, però tot el que ella és dins del projecte educatiu i polític que la societat democràtica li ha encomanat. 
L'escola no ha de perdre de vista que la seva funció principal és la d'ensenyar i donar eines per participar en una societat democràtica i plural, on la integració no és una qüestió que afecta solament l'alumnat d'origen estranger, sinó que és un procés que ha de posar-se a l'abast de tot l'alumnat com a mitjà per combatre el fracàs escolar i l'exclusió. Cal entendre que «l'escola, de fet, es troba presa entre un objectiu de normalització i el respecte a la diversitat, entre el reconeixement de la diversitat i el consens» (Abdallah-Pretceille, 1993: 45).

Recollint el que fins ara s'ha exposat, s'entén per integració escolar un procés comprensiu dirigit a donar espai per al desenvolupament personal, cultural i social de l'alumnat, a través de la participació en la vida docent i amb la finalitat de facilitar la integració social i laboral. L'escola, per afavorir la integració, ha de tenir presents les circumstàncies socials, culturals, educatives i psicològiques en què viu l'alumnat (Palaudàrias i Feu, 1997).

La integració escolar s'ha d'entendre dins d'un procés global de socialització en el qual cal diferenciar dos nivells. El primer nivell comprèn l'experiència i les relacions viscudes a l'àmbit de l'escola, i ha de recollir la situació a l'aula $\mathrm{i}$ en la diversitat d'activitats que es realitzen en el centre i des del centre. El segon nivell dóna sentit al primer, ja que entén que la integració s'ha d'avaluar en funció de l'eficàcia social que l'escola ha demostrat que té per servir la societat, entesa, bàsicament, a través del món laboral i de les relacions socials i culturals; en definitiva, la inserció sociolaboral.

L'escola, per aconseguir la integració en el seu àmbit, ha de plantejar-se (Abdallah-Pretceill, 1993):

1. Que la diversitat del teixit social que la institució acull ha canviat perquè l'alumnat ara és més divers que abans per les característiques pròpies, però també perquè la mateixa societat ha reflexionat sobre les seves característiques i capacitats.

2. El paper de les fronteres entre l'espai públic i el privat per mantenir l'equilibri i la cohesió del projecte col-lectiu que desenvolupa s'ha de modificar. Cal tenir en compte el projecte identitari de l'alumnat i el projecte educatiu de les famílies.

3. La necessitat d'impulsar el diàleg amb les famílies per tal d'aconseguir la participació activa a l'escola i l'intercanvi dels projectes educatius entre els usuaris i la institució és una necessitat de primer ordre. La comprensió mútua entre els actors de la integració facilitarà la transformació dels projectes educatius vers un de global que recollirà els individuals i afavorirà la identificació de l'alumnat amb el projecte escolar.

\section{Bases per a la integració escolar}

Exposada la conceptualització d'integració escolar, esmentats els seus eixos i analitzats els condicionants i les limitacions de la integració escolar, resta per descriure quins són els elements i les accions fonamentals per aconseguir posar 
les bases d'una acció socioeducativa que respongui a les demandes i a les necessitats de la societat.

Un primer requisit és que el projecte d'integració es basi en uns valors que l'escola ha de treballar a través del debat i de la formació, per tal de comprendre, per exemple, l'absència de l'alumnat musulmà els dies en què se celebren algunes de les festes més importants del seu calendari, el paper de la família en la relació amb la institució o el valor de l'educació escolar per a unes persones que potser no han viscut aquesta institució.

Aquests valors poden transmetre's a través d'una educació cívica, basada en els valors democràtics i en els referents que ens aporta la Declaració Universal dels Drets Humans, que ha de plantejar a la institució i a la col-lectivitat la necessitat d'abordar el debat sobre els conflictes i les contradiccions del procés educatiu, perquè el treball sobre aquests serà la base de la cohesió necessària per tal de fonamentar el projecte col-lectiu sobre el qual ha de basar-se la integració. Aquests tipus d'aprenentatges facilitaran que l'escola i, particularment, la integració escolar no siguin viscudes com un procés amenaçador de les particularitats, i alhora pot despullar el procés integrador de la problemàtica que representa per a uns infants $\mathrm{i}$ joves que es troben entre l'autoritat del discurs familiar, el de l'escola i el dels iguals.

El segon element sobre el qual s'ha de construir la integració escolar és la necessitat que el centre docent dinamitzi el diàleg amb les famílies partint del fet que no es poden posar totes sota els mateixos paràmetres. Es dóna una varietat de situacions que l'escola comprendrà quan estableixi un diàleg que té com a referents (Gaignard, 1992; Sammut, 1994):

- Impulsar el projecte d'integració tenint en compte la dimensió escola-família, apropant les famílies i els alumnes en el procés d'escolarització.

- Acostumar els pares a descobrir un espai de diàleg a l'escola, tenint present el bagatge social i cultural per tal d'associar la vida familiar al centre docent i afavorint la relació entre les associacions de pares i mares, el professorat $\mathrm{i}$ les famílies dels alumnes d’origen immigrant.

- Reduir la distància entre els codis lingüístics de la família i la cultura i els aprenentatges escolars; a través d'un acolliment comprensiu i afectiu amb les famílies.

- Dotar l'escola d'aquells professionals necessaris per tal d'aconseguir l'èxit del projecte social del centre.

Aquestes accions poden substituir l'actual i en alguns aspectes soterrada conflictivitat que es dóna en algunes escoles i que es manifesta, per exemple, a través de rivalitats per obtenir alguns beneficis socials que s'aconsegueixen a través de l'escolarització, per un principi de solidaritat i de comprensió que dugui a la superació dels estereotips i de les concepcions estàtiques de les cultures.

Dins d'aquest procés de renovació social i educativa, caldrà també tenir en compte que entre l'alumnat es donaran comportaments de resistència a l'acció 
de l'escola, perquè aquesta pretén enderrocar alguns elements de la cultura que viuen i sobre la qual han construït els estereotips i les referències, per exemple, d'home i dona, així com de treballador i món laboral. També perquè la situació i la seva experiència familiar i social invalida el discurs escolar. I en ocasions perquè el discurs de l'escola està allunyat de la realitat social que l'envolta. Per altra banda, també s'ha observat (Ogbu, 1996; Peralta, 2000) que l'alumnat de minories culturals defuig les actituds i els comportaments necessaris per resoldre amb èxit els seus estudis i la seva situació escolar, perquè són assimilats als propis de l'alumnat de la classe dominant i contraris als considerats com a propis, ja sigui d'una minoria cultural o d'una altra, ja que aquestes, a causa de les discriminacions i l'exclusió, s'han construït per oposició a la dominant.

\section{Conclusions}

Abordar la integració de l'alumnat d'origen immigrant a les escoles és un repte que presenta un important nivell de complexitat que requereix unes accions decidides no solament a l'àmbit escolar, sinó que aquestes accions han d'incidir en altres àmbits, com els drets civils i polítics. Lactual Llei d'estrangeria és un obstacle important per a la integració plural.

Però els centres educatius no poden esperar que algunes d'aquestes condicions es donin. Més aviat han de plantejar-se unes prioritats, tenint en compte que és necessari intervenir tant en el procés d'aprenentatge, com en els aspectes socioculturals que envolten la vida del centre. Difícilment s'incidirà en els aspectes formatius si s'abandona, per exemple, l'acció pedagògica que ha de dur a la necessària comprensió, per part dels pares, de quin valor té l'escola que es fonamenta en una dimensió pública i acollidora de tot el teixit social, i també si no se'ls explica què succeeix dins del seu espai, ja que cal tenir en compte que per a moltes famílies d'origen immigrant l'escola com a institució és una desconeguda i, per a alguns, és una institució contrària a una bona part dels seus valors educatius.

Cal treballar per transmetre la necessitat de la seva participació escolar i també la de tothom, en aquest sentit cal ser creatius per tal de transformar el concepte tradicional de participació. I també caldrà treballar, amb tanta força com en l'aprenentatge de les llengües per part de l'alumnat, en la connexió que ha d'existir entre l'escola i la família, qüestionant el concepte d'educació basat en el d'un producte de consum més.

Ens cal una escola amb un projecte obert a tota la societat i, per tant, conscient dels obstacles i de les seves limitacions. En aquest sentit, l'escola ha de passar de ser un lloc de pas a un lloc de trobada, on el diàleg entre els diferents agents educatius sigui la base per construir el paper integrador que l'escola pot realitzar. Una funció integradora que no és igual a homogeneïtzació i que ha de saber respectar les particularitats de les minories culturals, per exemple, en els temes religiosos.

Avui no té sentit mantenir l'escola com a institució legitimadora de la cultura dominant, perquè aquesta funció és qüestionada per la diversitat de 
mitjans educatius amb els quals coexisteix. El paper que escola ha de realitzar en l'actualitat és una tasca de mediació entre les cultures que doni la possibilitat de construir una cultura de la convivència i que ha de tenir present una visió de les circumstàncies que afecten tota la humanitat.

\section{Bibliografia}

AbDalah-Pretceille, M. (1993). Quelle école pour quelle integration? París: Hachette. BESALÚ, X. (1998). «Currículum nacional y currículum intercultural en Cataluña y España». A BeSALÚ, X.; PALAUdÀRIAS, J.M. i altres. La educación intercultural en Europa. Barcelona: Pomares-Corredor, p. 153-170.

CARBONELl, F. (coord.) (2000). Educació i immigració. Els reptes educatius de la diversitat cultural i l'exclusió social. Barcelona: Mediterrània.

Costa-Lascoux, J. (1991). De l'immigré au citoyen. París: La Documentation française. DEPARTAMENT D'ENSENYAMENT (1996). Educació intercultural. Barcelona: Generalitat de Catalunya.

GAIGNARD, F. (1992). «Trois ans d'actions pour favoriser la rélation école-famille». Cahiers pedagogiques, 309, p. 39. París: CRAP.

LIAZU, C. (1992). Race et civilisation. L'autre dans la culture occidental, anthologie historique. París: Syros.

Malgesini, G.; GiméneZ, C. (1997). Guia de conceptos sobre migraciones, racismo y interculturalidad. Madrid: La Cueva del Oso.

NoIriel, G. (1989). «Les jeunes d'origine immigré n'existent pas». A LORREYTE, B. (dir.). Les politiques d'integration des jeunes issus de l'immigration. París: L'Harmattan, p. 211-221.

OGBu, J.U. (1996). «Educazione e stratificacione sociale». A GobBo, F. (coord.). Antropologia dell'edcazione. Scuola, cultura, educazione nella società multicurale. Milà: Unicopoli, p. 113-126.

PALAUdÀRIAS, J.M.; FEU, J. (1997). «La acogida del alumnado extranjero en las escuelas públicas. Una reflexión necesaria para favorecer la integración plural». A GarCía, F.J.; Granados, A. (comp.). Educación o exclusión de la diversidad? Granada: Universidad de Granada, p. 35-47.

Peralta, A. (2000). La adaptación al ámbito escolar de hijos de inmigrantes marroquies. Universitat Autònoma de Barcelona. Manuscrit. Tesi doctoral.

Roux, M. (1989). «Du bon usage de jeunes gens trop remuants». A LORREYTE, B. (dir.). Les politiques d'integration des jeunes issus de l'immigration. París: L'Harmattan, p. 293-311.

Sammut, C. (1994). «Avec les parents: l'échange comme méthode». Cahiers pedagogiques, 38, p. 25-26. París: CRAP.

TABBONI, S. (1996). «Sociologia dello straniero, sociologia del razzismo e dell'etnicità essenzialista». DE FINIS, G.; SCARTEZZINI, R. (coord.). Universalità \& differenza. Cosmopolitismo e relativismo nelle realzioni tra identità sociali e culture. Milà: Franco Angeli, p. 235-254.

Touraine, A. (1994). Qu'est-ce que la démocratie? París: Fayard. 